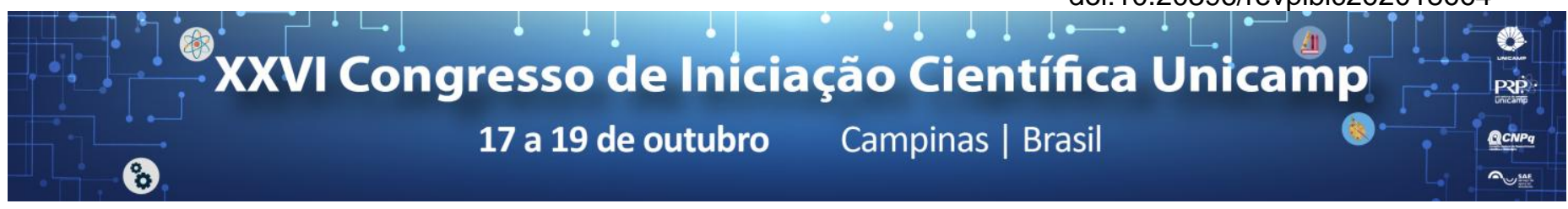

\title{
Qualidade de voz após reconstrução laringotraqueal em crianças
}

\section{Jéssica Estefanya Batista*, Ana Carolina Constantini, Rebecca Maunsell, Nayara Soares.}

\section{Resumo}

O objetivo geral do estudo foi verificar a qualidade vocal de crianças pós reconstrução laringotraqueal e o objetivo específico foi conhecer a percepção dos pais ou cuidadores sobre a voz de crianças que passaram por reconstrução laringotraqueal e analisar, por meio de avaliação perceptivoauditiva, a qualidade vocal pós-reconstrução laringotraqueal. Através da aplicação do Protocolo Qualidade de Vida em Voz Pediátrico (QVV-P) e da avaliação vocal seguindo protocolo do Consenso da Avaliação Perceptivo auditiva da voz - CAPE-V (ASHA 2003) a análise da qualidade vocal destas crianças evidenciou alterações de grau moderado, justificando, possivelmente, o prejuízo na qualidade de vida.

Palavras-chave: Reconstrução laringotraqueal; qualidade vocal; percepção de pais/cuidadores; estenose laringotraqueal

\section{Introdução}

A estenose laringotraqueal (ELT) ocorre quando há redução do calibre das vias aéreas. O foco do tratamento da ELTT é o desenvolvimento de uma via aérea adequada com preservação ou melhoria da qualidade vocal e, para isso, as opções cirúrgicas são individualizadas. O objetivo geral do estudo foi verificar a qualidade vocal de crianças pós reconstrução laringotraqueal e o objetivo específico foi conhecer a percepção dos pais ou cuidadores sobre a voz de crianças que passaram por reconstrução laringotraqueal e analisar, por meio de avaliação perceptivoauditiva, a qualidade vocal pósreconstrução laringotraqueal.

\section{Resultados e Discussão}

Através da aplicação do Protocolo Qualidade de Vida em Voz Pediátrico (QVV-P) ${ }^{1}$ e a realização da gravação da voz dos participantes em cabine acústica seguindo protocolo do Consenso da Avaliação Perceptivo auditiva da voz - CAPE-V (ASHA 2003)² enviada à dois juízes fonoaudiólogos com experiência em voz para a análise perceptivoauditiva. Seguindo os critérios de inclusão e exclusão, 19 crianças iniciaram a participação na pesquisa. A idade média foi de seis anos e um mês e o tempo desde a última abordagem cirúrgica ficou entre $3 \mathrm{e}$ 58 meses, com a média de 23 meses.

\section{PROTOCOLO DE QUALIDADE DE VIDA EM VOZ NA POPULAÇÃO PEDIÁTRICA}

Foi observado que nos trêm âmbitos do protocolo (geral, socio-emocional e físico) o escore médio alcançado pelos participantes ficou abaixo da nota de corte estabelecida na validação brasileira, indicando pior índice de qualidade de vida relacionada à voz

Tabela 1: Protocolo de Qualidade de Vida em Voz

\begin{tabular}{ccccc}
\hline & Mínimo & Média & Máximo & Nota de corte \\
\hline Geral & 42,5 & 75,8 & 100 & 78,65 \\
Sócio-Emocional & 31,3 & 80,6 & 100 & 85,37 \\
Físico & 37,5 & 72,6 & 100 & 73,78 \\
\hline
\end{tabular}

\section{ASPECTOS DE LINGUAGEM}

Dentre os participantes da pesquisa, cinco crianças $(26,3 \%)$ possuíam alterações de linguagem que inviabilizaram a aplicação do protocolo CAPE-V. Nesta parcela da amostra, foram observadas vocalização com intenção comunicativa e produção de palavras isoladas.

\section{ANÁLISE PERCEPTIVO AUDITIVO DA QUALIDADE VOCAL}

Tabela 2. Avaliação perceptivo auditiva com o protocolo CAPE-V

\begin{tabular}{lrrrr}
\hline & Grau geral & Soprosidade & Rugosidade & \multicolumn{1}{c}{ Tensão } \\
\hline Média & 63,92 & 63,73 & 45,60 & 52,23 \\
Mínimo & 35,75 & 34,00 & 23,50 & 30,00 \\
Máximo & 90,00 & 87,50 & 74,50 & 85,00 \\
Desvio Padrão & 19,13 & 19,71 & 15,53 & 17,47 \\
\hline
\end{tabular}

Classificação da qualidade vocal do protocolo CAPE-V

\begin{tabular}{|c|c|c|c|c|}
\hline Normal ou adaptada & Desvio Leve & Desvio moderado & Desvio intenso \\
\hline 35,5 & 50,5 & 90,5 & VIEIRA et al (2013)
\end{tabular}

\section{Conclusões}

O procedimento de RLT gerou, nos participantes desta pesquisa, alteração da qualidade de vida relacionada à voz. A análise da qualidade vocal destas crianças evidenciou alterações de grau moderado, justificando, possivelmente, o prejuízo na qualidade de vida.

Por outro lado, algumas crianças não realizaram todos os procedimentos previstos inicialmente devido a dificuldades globais e alterações de linguagem. Assim, além da reabilitação da qualidade vocal, crianças que passam por RLT devem ser encaminhadas à terapia fonoaudiológica para avaliação de aspectos de linguagem e desenvolvimento.

\section{Agradecimentos}

Agradeço ao Conselho Nacional de Desenvolvimento Científico e Tecnológico pelo apoio financeiro que tornou possível a realização da pesquisa. Agradeço também ao Hospital das Clínicas da Universidade Estadual de Campinas pela autorização da pesquisa e aqueles que se dispuseram a participar dela. Por fim, agradeço a equipe toda, a orientadora e a co-orientadora da pesquisa pelo apoio durante todo o percurso.

\footnotetext{
${ }^{1}$ RIBEIRO, L L; PAULA, K. M. P.; BEHLAU, M. Qualidade de Vida em Voz na População Pediátrica: validação da versão brasileira do Protocolo Qualidade de Vida em Voz Pediátrico. Revista CoDAS, São Paulo, v. 26, n. 1, p. 87-95, Feb. 2014

${ }^{2}$ Consensus auditory-perceptual evaluation of voice (CAPE-V), ASHA 2003 Revista Sociedade Brasileira de Fonoaudiologia. 2004;9(3):187-9.
} 